\title{
Den norske EPOC-satellitten: støtte til kunnskapsbaserte beslutninger
}

\author{
Susan Munabi-Babigumira, Marit Johansen og Elizabeth Paulsen \\ Seksjon for global helse, Nasjonalt Kunnskapssenter for helsetjenesten \\ Korrespondanse: Susan Munabi-Babigumira e-post: susan.munabi-babigumira@kunnskapssenteret.no Telefon: 46400471
}

\begin{abstract}
SAMMENDRAG
Systematiske oversikter fra det internasjonale Cochrane-samarbeidet er en viktig kilde til oppsummert kunnskap for beslutningstakere i helsevesenet. Den norske satellitten av Cochrane Effective Practice and Organisation of Care (EPOC) Review Group har base i Seksjon for global helse, Nasjonalt kunnskapssenter for helsetjenesten, og fokuserer på tiltak som retter seg mot helsesystemer og helsetjenesten i lav- og mellominntektsland. Den norske EPOC-satellitten gir redaksjonell støtte til forfattere som skriver Cochraneoversikter om effekter av slike tiltak, og bidrar dermed til at systematiske oversikter blir utarbeidet og brukt. Behovet for oppsummert kunnskap, skreddersydd for ulike sammenhenger og ulike sluttbrukere, er stort. Ikke minst gjelder det i lav- og mellominntektsland der ressursene er begrenset, og der gode prioriteringer er spesielt viktig.
\end{abstract}

Munabi-Babigumira S, Johansen M, Paulsen E. The Norwegian EPOC-satellite: Support for evidenceinformed decisions. Nor J Epidemiol 2013; 23 (2): 211-214.

\section{ENGLISH SUMMARY}

Systematic reviews from the Cochrane Collaboration are an important source of summarised evidence for decision makers in health care. The Norwegian satellite of the Cochrane Effective Practice and Organisation of Care (EPOC) Review Group has its base at the Global Health Unit in the Norwegian Knowledge Centre for the Health Services, and focuses on interventions targeting health systems and services in lowand middle-income countries. The Norwegian EPOC-satellite provides editorial support to authors who write systematic reviews on the effects of such interventions, and contributes to building the capacity for producing and using systematic reviews. The need for summarised evidence, tailored for various settings and various end users, is large. This is particularly important for low- and middle income countries, where resources are limited and it is important to identify the right priorities.

This is an open access article distributed under the Creative Commons Attribution Licence, which permits unrestricted use, distribution, and reproduction in any medium, provided the original work is properly cited.

\section{INTRODUKSJON}

"If you are poor, you actually need more evidence, before you invest, rather than if you are rich"

(Dr. H. Mshinda, Ifakara Centre, Tanzania).

\section{Cochrane-samarbeidet}

Beslutningstakere på alle nivåer i helsetjenesten trenger kunnskap om effekt av tiltak for å kunne ta velinformerte beslutninger, og for å kunne sette disse beslutningene ut i livet. Systematiske oversikter fra det internasjonale Cochrane-samarbeidet er én kilde til slik kunnskap.

De fleste Cochrane-oversikter omhandler effekt av ulike kliniske behandlingstiltak, men også effekt av ikke-kliniske forbedringstiltak blir oppsummert gjennom Cochrane-samarbeidet. Oversiktene blir fortløpende publisert $i$ The Cochrane Library, som er gratis tilgjengelig for alle i Norge (1). Cochrane-samarbeidet er et nettverk av forskere, klinikere og andre som jobber sammen om å utarbeide, oppdatere og gi tilgang til systematiske oversikter om effekten av helsetjenester. Organisasjonen er inndelt i tematiske "review groups", hvor de fleste er orientert mot kliniske problemstillin- ger, for eksempel Injuries Group og Neonatal Group, mens andre dreier seg om ikke-kliniske problemstillinger, for eksempel Public Health Group og Effective Practice and Organisation of Care Group.

\section{The Cochrane Effective Practice and Organisation of Care (EPOC) Review Group}

Effective Practice and Organisation of Care (EPOC) er navnet på Cochrane-gruppa som utgir systematiske oversikter som omhandler tiltak innen kvalitetsforbedring, organisering, regulering og finansiering av helsetjenester (2).

\section{DEN NORSKE EPOC-SATELLITTEN}

Den norske satellitten av EPOC har base i Seksjon for global helse ved Nasjonalt kunnskapssenter for helsetjenesten, og fokuserer på tiltak som retter seg mot helsesystemer og helsetjenesten i lav- og mellominntektsland (3). Satellittens primæroppgave er å støtte oversiktsforfattere som enten kommer fra et lav- eller mellominntektsland, eller som arbeider med oversikter som fokuserer på problemstillinger med relevans for 


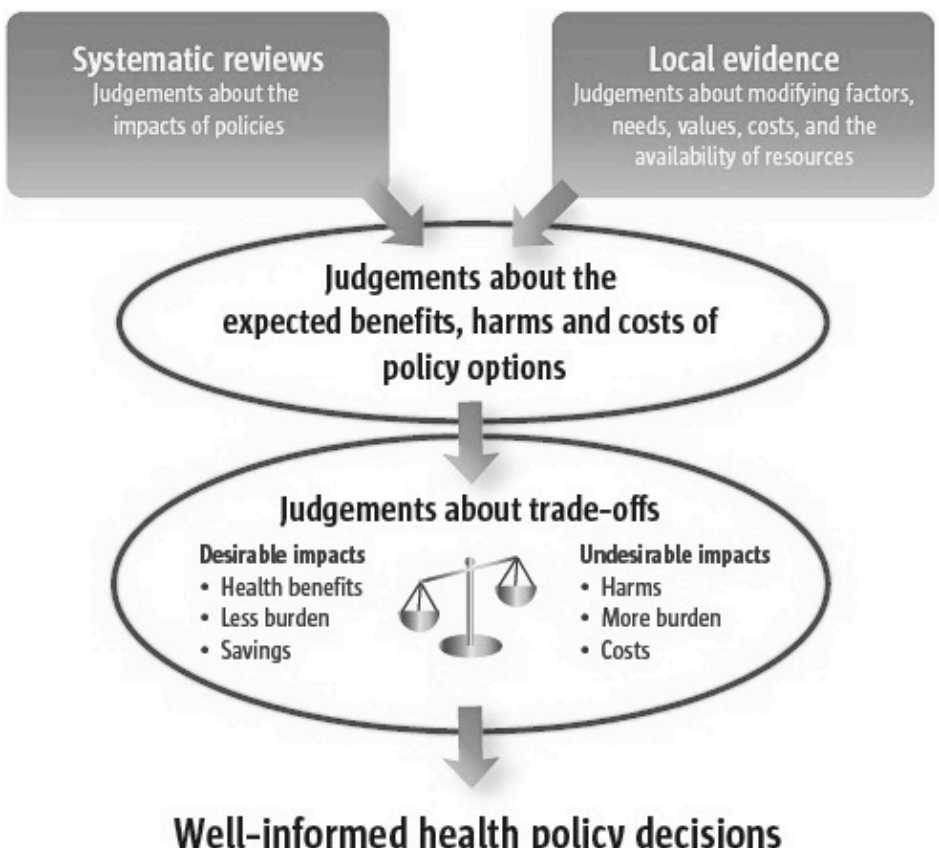

Figur 1. Bruk av forskningsbasert kunnskap i helsepolitiske beslutninger (4).

lav- og mellominntektsland. I tillegg driver satellitten et betydelig utviklingsarbeid for å bedre metodene for å utarbeide systematiske oversikter - både Cochraneoversikter generelt, og EPOC-oversikter spesielt. Blant medarbeiderne $\mathrm{i}$ satellitten er det en administrativ redaktør, flere fagredaktører, en forskningsbibliotekar, og en statistiker.

I tillegg til å utarbeide systematiske oversikter, spiller satellitten også en sentral rolle i en serie prosjekter der målet er å bedre mulighetene for beslutningstakere i lav- og mellominntektsland til å bruke forskningsbasert kunnskap, både på lokalt og nasjonalt nivå. Figur 1 illustrerer hvordan forskningsbasert kunnskap kan inngå i politiske beslutningsprosesser.

\section{A bygge kapasitet}

For å bidra til mer bruk av forskning i beslutningsprosesser, kanskje særlig i land der kunnskapsbasert praksis fortsatt er lite innarbeidet, trengs det individer som kan gå i bresjen, og som etterspør og bruker forskningsbasert kunnskap når beslutninger skal tas (5). Det er også behov for å bygge kapasitet gjennom nettverk både med enkeltpersoner og institusjoner som ønsker å bidra til kunnskapsbaserte beslutninger. Den norske EPOC-satellitten bidrar til slik kapasitetsbygging, blant annet gjennom stipendieordninger og workshops.

\section{Stipendier}

Gjennom vårt samarbeid med WHO Alliance for Health Systems and Policy Research, og med økonomisk støtte fra Norad, kan EPOC-satellitten invitere forfattere av Cochrane-oversikter til å delta i arbeidsmøter med redaksjonsgruppa i Oslo. Foruten redaksjonell støtte kan satellitten også tilby veiledning i det å skrive systematiske oversikter, det vil si, finne relevant litteratur, kvalitetsvurdere og gradere styrken på den, og sammenstille og oppsummere den.

Tre eksempler på Cochrane-oversikter som er utarbeidet med faglig støtte og oppfølging fra den norske satellitten er: "Interventions to reduce emigration of health care professionals from low- and middleincome countries" (6), "Paying for performance to improve the delivery of health interventions in low- and middle-income countries" (7), og "Interventions for improving coverage of child immunization in low- and middle-income countries" (8).

\section{Workshops}

Satellitten har organisert workshops rettet mot et bredere publikum der både beslutningstakere, forskere, journalister og andre har deltatt. I 2012 ble det avholdt en workshop i Addis Abeba, Etiopia, der målsettingen var å videreutvikle og dele ressurser som støtter opp om kunnskapsbasert politikkutforming innen helse i lav- og mellominntektsland (9).

\section{Prioriteringer}

Det er stor etterspørsel etter systematiske oversikter. For å kunne prioritere blant de mange problemstillingene som blir foreslått, er det nødvendig å identifisere de områdene der behovet for systematiske oversikter er størst. EPOC-satellitten har derfor samlet systematiske oversikter (ikke bare fra Cochranesamarbeidet) som er relevante for EPOCs tematiske område, og gjort disse gratis tilgjengelige for alle i databasen PDQ-Evidence (10). Basert på en gjennomgang av denne databasen er det laget en prioriteringsliste (11). Med en slik liste kan man unngå dobbeltarbeid, avdekke oversikter som er utdaterte og trenger 
å bli oppdatert, og påvise kunnskapshull - områder der en systematisk oversikt mangler.

\section{KUNNSKAP I ET BRUKERVENNLIG FORMAT}

Forskningsbasert kunnskap i form av systematiske oversikter er ofte lite brukervennlige, og kan være svært krevende å forstå. Å oversette forskningen til et språk og et format som enhver sluttbruker kan håndtere er derfor nødvendig og avgjørende for om kunnskap fra systematiske oversikter blir brukt. Her følger noen eksempler på brukervennlige formater som EPOC-satellitten har vært med på å utvikle.

\section{SUPPORT}

Det EU-finansierte prosjektet SUPPORT ble etablert for å støtte bruk av systematiske oversikter i arbeidet for å bedre mødre- og barnehelse (12). Gjennom dette prosjektet samarbeider satellitten med kollegaer i SørAfrika, Chile, Colombia og Argentina for å produsere sammendrag av systematiske oversikter der målgruppa er beslutningstakere, blant annet på helsepolitisk nivå. Disse sammendragene omfatter også informasjon om hvor anvendbar kunnskapen er med tanke på situasjonen i mange lav- og mellominntektsland, hvordan tiltaket kan innvirke på sosiale ulikheter i helse, kostnader knyttet til tiltaket, behovet for monitorering og evaluering, og en "summary of findings" tabell der resultatene fra den systematiske oversikten kommer tydelig fram (13). Formatet som brukes som mal for disse sammendragene ble utviklet på bakgrunn av en brukertest der beslutningstakere fra ulike land deltok.

\section{SURE}

SURE står for "Supporting the Use of Research Evidence in African Health Systems", og er et annet eksempel på et samarbeidsprosjekt i Afrika, der hensikten er å bidra til kunnskapsbasert politikkutforming (14). Prosjektteamet består av forskere og beslutningstakere fra sju afrikanske land med støtte fra forskere ved McMaster-universitetet i Canada, Karolinska Institutet i Sverige, Verdens helseorganisasjon (WHO), og fra EPOC-satellitten ved Nasjonalt kunnskapssenter for helsetjenesten. I dette prosjektet utvikles flere strategier for "knowledge translation", blant annet Evidencebased policy briefs, Policy-dialoger og Rapid response services.

\section{Evidence-based policy briefs}

Et Evidence-based policy brief er en type rapport som tar utgangspunkt $\mathrm{i}$ et prioritert tema eller et forskningsspørsmål som en beslutningstaker, gjerne på politisk nivå, ønsker å få besvart. Når spørsmålet er klart formulert innhentes kunnskap som kan bidra til å besvare det. Denne kunnskapen kan komme fra ulike kilder, fra systematiske oversikter, fra primærstudier og fra lokale kunnskapskilder (for eksempel helseregistre). I et policy brief vil ulike handlingsalternativer bli presentert, basert på den samlede kunnskapen.
Team fra flere afrikanske land har fått metodologisk og redaksjonell støtte fra den norske EPOC-satellitten til i å utvikle slike Evidence-based policy briefs. Eksempler på slike policy briefs er "Task shifting to optimise the roles of health workers to improve the delivery of maternal and child healthcare" (15), "Strengthening the health system for mental health" (16), og "Strategies to reduce maternal mortality" (17). Metodene som brukes i utarbeiding av Evidence-based policy briefs er beskrevet i SURE Guides to EvidenceBased Policy Briefs (18).

\section{Policy-dialoger}

Gjennom en policy-dialog ønsker man å legge til rette for samarbeid mellom beslutningstakere og forskere. Slike dialoger gir de ulike aktørene innsikt $\mathrm{i}$ et bredt kunnskapsgrunnlag, med anledning til å vurdere ulike muligheter for hvordan denne kunnskapen kan tas i bruk. SURE-prosjektet har arrangert flere policydialoger basert på utarbeidede policy briefs. Rapportene fra disse dialogene er fritt tilgjengelige fra SUREs webside (14). Metodene som brukes for å planlegge og gjennomføre en policy-dialog er beskrevet $i$ the SURE Guides (18).

\section{Rapid response service}

Ofte er det slik at en beslutningstaker trenger svar på et forskningsspørsmål i løpet av svært kort tid. Hvis det er snakk om en frist på dager eller få uker, vil det ikke være mulig å utarbeide en systematisk oversikt over aktuell forskningslitteratur. Rapid response services, en tjeneste for å møte behovet for svar med korte frister, har derfor blitt utviklet i fire land i forbindelse med SURE-prosjektet: i Burkina Faso, Kamerun, Zambia og Uganda (19). Tilbakemeldingene fra brukere av tjenesten i Uganda er positive, så langt. Erfaringene viser at en slik tjeneste er nyttig og ikke minst mulig å drifte $i$ et lavinntektsland. En formell evaluering av disse tjenestene, som også inkluderer kostnader, er i gang.

\section{VERKTØY SOM STØTTER BESLUTNINGS- PROSESSER}

Beslutningstakere som vil sette kunnskap ut i livet trenger verktøy for å få dette til på en god måte. "Developing and evaluating communication strategies to support informed decisions and practice based on evidence (DECIDE)", er et prosjekt som EPOCsatellitten i Oslo for tiden deltar i, og der formålet er å bidra til at forskningsbasert kunnskap blir brukt på en systematisk og transparent måte i beslutningsprosesser (20). I DECIDE utvikles et rammeverk for å hjelpe beslutningstakere til å vurdere og avveie fordelene og ulempene som er knyttet til forskjellige tiltak. Tanken er at dette vil strukturere diskusjonen og avklare hva som ligger til grunn for eventuelle uenigheter. Kunnskapsgrunnlaget for avgjørelser som blir tatt gjennom en slik prosess vil bli tydelige og transparente for alle involverte parter. DECIDE-rammeverket har blitt brukt 
i retningslinjer utviklet av WHO (21), og blir nå utprøvd i Latin-Amerika.

\section{KONKLUSJON}

Behovet for oppsummert kunnskap, skreddersydd for ulike settinger og ulike sluttbrukere, er stort. Dette gjelder ikke minst i lav- og mellominntektsland, der ressursene er begrenset, og der gode prioriteringer er spesielt viktig. Forskere trenger støtte for å kunne utarbeide systematiske oversikter, og beslutningstakere trenger støtte for å kunne ta systematiske oversikter $\mathrm{i}$ bruk. Å bidra med slik støtte er hovedmålet til den norske EPOC-satellitten.

\section{REFERANSER}

1. The Cochrane Library [database]. The Cochrane Collaboration. www.thecochranelibrary.com (04.07.13).

2. The Cochrane Effective Practice and Organisation of Care (EPOC) Review Group. The Cochrane Collaboration. http://epoc.cochrane.org/ (04.07.13).

3. The Norwegian satellite of the Cochrane Effective Practice and Organisation of Care (EPOC) Review Group. The Cochrane Collaboration. http://epocoslo.cochrane.org/ (04.07.13).

4. Oxman AD, Lavis JN, Lewin S, Fretheim A. SUPPORT Tools for evidence-informed health Policymaking (STP): 1. What is evidence-informed policymaking? Health Res Policy Syst 2009; 7 (Suppl 1): S1.

5. Lomas J. The in-between world of knowledge brokering. BMJ 2007; 334: 129-32.

6. Peñaloza B, Pantoja T, Bastías G, Herrera C, Rada G. Interventions to reduce emigration of health care professionals from low- and middle-income countries. Cochrane Database Syst Rev 2011; 9: CD007673.

7. Witter S, Fretheim A, Kessy FL, Lindahl AK. Paying for performance to improve the delivery of health interventions in low- and middle-income countries. Cochrane Database Syst Rev 2012; 2: CD007899.

8. Oyo-Ita A, Nwachukwu CE, Oringanje C, Meremikwu MM. Interventions for improving coverage of child immunization in low- and middle-income countries. Cochrane Database Syst Rev 2011; 7: CD008145.

9. Report on International Forum on evidence informed health policy in low- and middle- income countries. Addis Ababa, Ethiopia - August 28th-30th, 2012. www.who.int/evidence/Addisreport2012.pdf (04.07.13).

10. PDQ-Evidence [database]. www.pdq-evidence.org (16.09.13).

11. Norwegian Satellite of the Cochrane Effective Practice and Organisation of Care Group. Priority topics. The Cochrane Collaboration. http://epocoslo.cochrane.org/priority-topics (16.09.13).

12. The SUPPORT collaboration. www.support-collaboration.org/ (04.07.13).

13. Rosenbaum SE, Glenton C, Wiysonge CS, Abalos E, Mignini L, Young T et al. Evidence summaries tailored for health policymakers in low and middle-income countries. WHO Bull 2011; 89: 54-61.

14. Supporting the Use of Research within African health systems (SURE Project). World Health Organization. www.who.int/evidence/sure/en/ (04.07.13).

15. Nabudere H, Asiimwe D, Mijumbi R. Task shifting in maternal and child health care: an evidence brief for Uganda. Int J Technol Assess Health Care 2011; 27: 173-179.

16. Mwape L, Mweemba P, Kasonde JM. Strengthening the health system for mental health (Policy Brief). The Zambia Forum for Health Research, Lusaka, 2010. www.who.int/evidence/sure/MentalhealthZambia.pdf (04.07.13).

17. Sanon/Ouédraogo D, Ki/Ouédraogo S, Kouyaté B, Stratégies porteuses pour la réduction de la mortalité maternelle au Burkina Faso (Note de politique SURE). Ouagadougou, Burkina Faso: Ministère de la santé, 2010. www.who.int/evidence/sure/MaternalMortalityBF.pdf (04.07.13).

18. SURE Guides for Preparing and Using Evidence-Based Policy Briefs. World Health Organization. www.who.int/evidence/sure/guides/en/ (16.09.13).

19. Uganda Clearing House for health policy and health systems research. A public resource for health policy and systems research evidence. http://uchpsr.org/rapid-response-summaries.php (04.07.13).

20. Developing and evaluating communication strategies to support informed decisions and practice based on evidence. DECIDE-Collaboration. www.decide-collaboration.eu/ (04.07.13).

21. WHO Recommendations - OPTIMIZEMNH. Optimizing health worker roles for maternal and newborn health. World Health Organization. http://optimizemnh.org/ (19.09.13). 